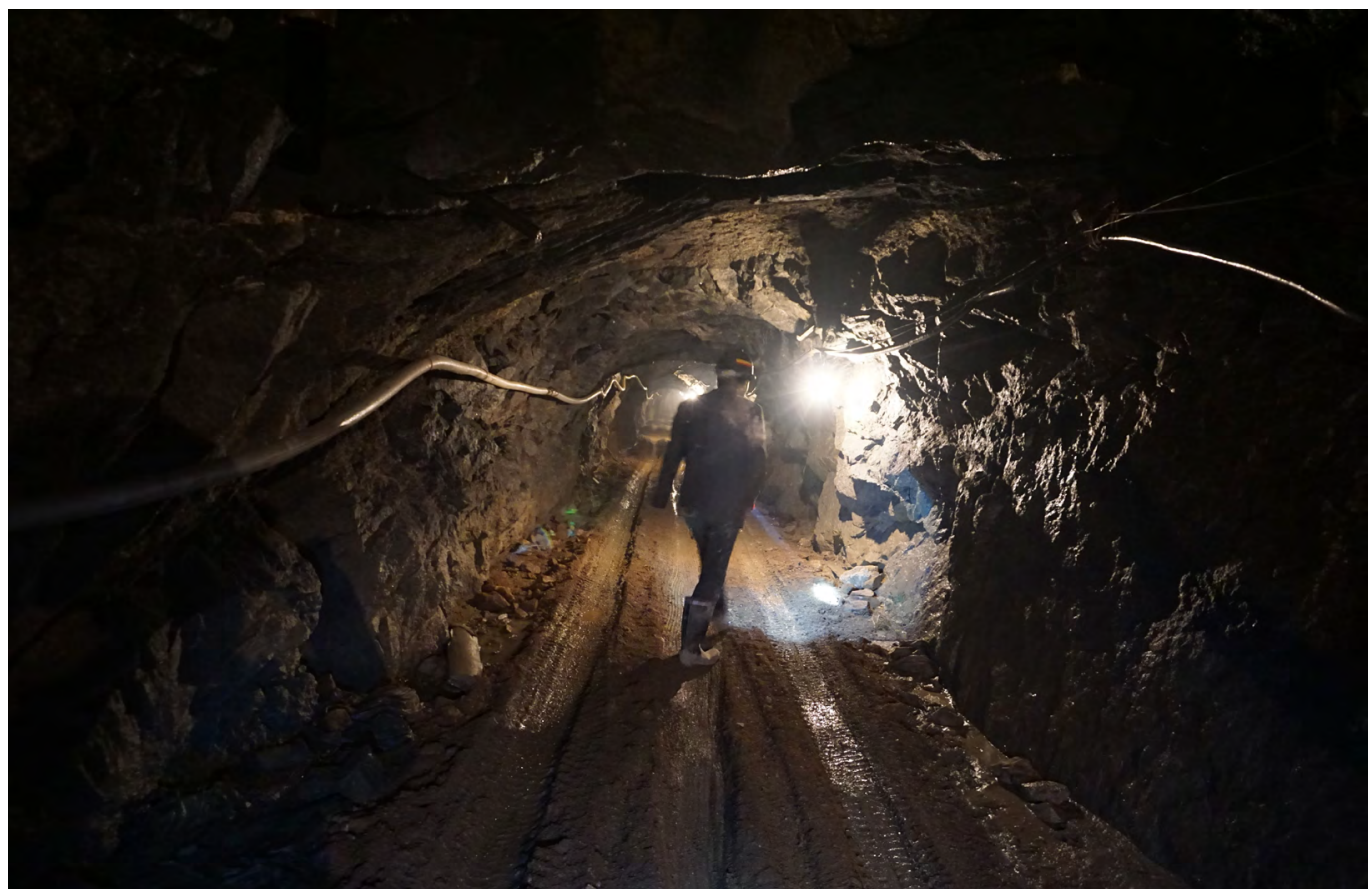

\section{The Double-} Tongued Dilemma

\author{
Translating Chinese Workers' \\ Relations in Mongolia
}

ZHU Ruiyi

Despite the ostensible complementarity of the structural shortage of industrial labour in Mongolia and the excess thereof in China, Chinese workers have constituted a source of anxiety in post-socialist Mongolia. Drawing on fieldwork at a Chinese-owned fluorspar mine in Mongolia between 2018 and 2019, this essay sheds light on the tension between bilingual and monolingual Chinese workers in the Sino-Mongolian industrial sphere. While the monolinguals rely on the bilinguals to facilitate industrial production, they also regard the latter in a suspicious light.
Chinese miner enters a drift. PC: Zhu Ruiyi.
L iu Xizhou, a Han Chinese truck driver in his late fifties from the Hohhot region in Inner Mongolia, is known among Mongols for his warm heart and his knowledge of the Mongolian language. ${ }^{1}$ Over seven years at a fluorspar mine on the eastern plains of Mongolia, he has cultivated a local network of friends and acquaintances. Younger Mongolian workers call him Ulzii ah ('elder brother' in Mongolian), and many extended family members of factory workers and exworkers who live in the nearby sum ('district') have heard of him. Liu often receives a barrage of personal requests for assistance from 
Mongolian workers. To his Chinese colleagues, Old Liu's willingness to help Mongolian workers, particularly female workers, counts as a penchant for liaisons dangereuses.

One day, the sixty-year-old manager old Wang, a native of Hunan province, paid a surprise visit to Liu's dormitory during dinnertime. Though they were never close, Liu invited Old Wang to partake in the hotpot he was hosting for friends-three Han Chinese workers and myself. After a few drinks, Old Wang threw a casual remark to Liu: 'You are popular with Mongolian women, aren't you? How many seeds have you sown in Mongolia?' The atmosphere became tense, as everyone understood the question's aggressive undertone. Liu put down his chopsticks and resolutely replied: 'Not even one.' Old Wang retorted: 'I don't believe it.' The other workers tried to deflect the tension by raising canned beers to toast: 'Bottoms up, bottoms up.' Liu tried to suppress his anger in front of the guests, but his flushed face gave away his true feelings. As soon as Wang left, Liu turned to speak to me and switched to Mongolian-a nonnative language for both of us: 'Tuunii yarisan yum[iig] chi sonsson uu?' (Have you heard his words?) Given our shared background as Chinese nationals, Liu's deliberate codeswitching to Mongolian acknowledged my ability to empathise with his outrage from the in-between position of a Mongolophone Chinese.

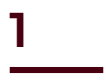

This vignette exposes the tension between bilingual and monolingual Chinese workers in the Sino-Mongolian industrial sphere. Drawing on fieldwork conducted at a Chineseowned mine and factory in Mongolia, this essay will reflect on the critical roles of language and translation as boundary-keeping and boundary-crossing practices in intra and interethnic labour relations. While the monolinguals rely on the bilinguals to facilitate industrial production, they also view the latter in a suspicious light-often refracted through the issue of sexual intimacy. ${ }^{2}$

Although Chinese workers are to various extents aware that sexuality is a sensitive issue in the historical and contemporary politics of the Sino-Mongolian interface, some still choose to express themselves and build sociality through sexual banter in Chinese. Despite making such utterances, they take pains to prevent their incendiary speech from reaching their Mongolian counterparts. The bilingual Chinese workers-privy to the off-limits banter-attempt to strike a delicate balance between ethnic affinity, corporate fidelity, and genuine interethnic communication.

Between 2018 and 2019, I conducted 18 months of fieldwork among Chinese and Mongolian workers in the Mongolian extractive economy. In the early 1990s, as the Soviet influence faded with market liberalisation, Mongolia's economy became quickly entwined with that of its southern neighbour China, which rose to become Mongolia's largest export destination and import partner. Since the mining boom of the mid-2000s, a significant portion of the mineral resources extracted in Mongolia-such as iron ore, copper concentrate, zinc concentrate, coal, and fluorspar-has been exported to China. A large number of Chinese companies, varied in size and ownership, also flocked to the Mongolian mining industry. Despite volatility on the global minerals market, mining remains a pillar of the Mongolian economy.

Along with Chinese financial investment in the Mongolian extractive economy, Chinese workers flowed into Mongolia, where there is a chronic shortage of skilled industrial labour. While overseas branches of Chinese state-owned enterprises draw on their domestic employee pool or established labour contractors, private companies rely heavily on informal kinship and locality networks for recruitment. A number of Chinese labour migrants to Mongolia were workers who had been laid off during the privatisation and automation processes of the late 1990s and 


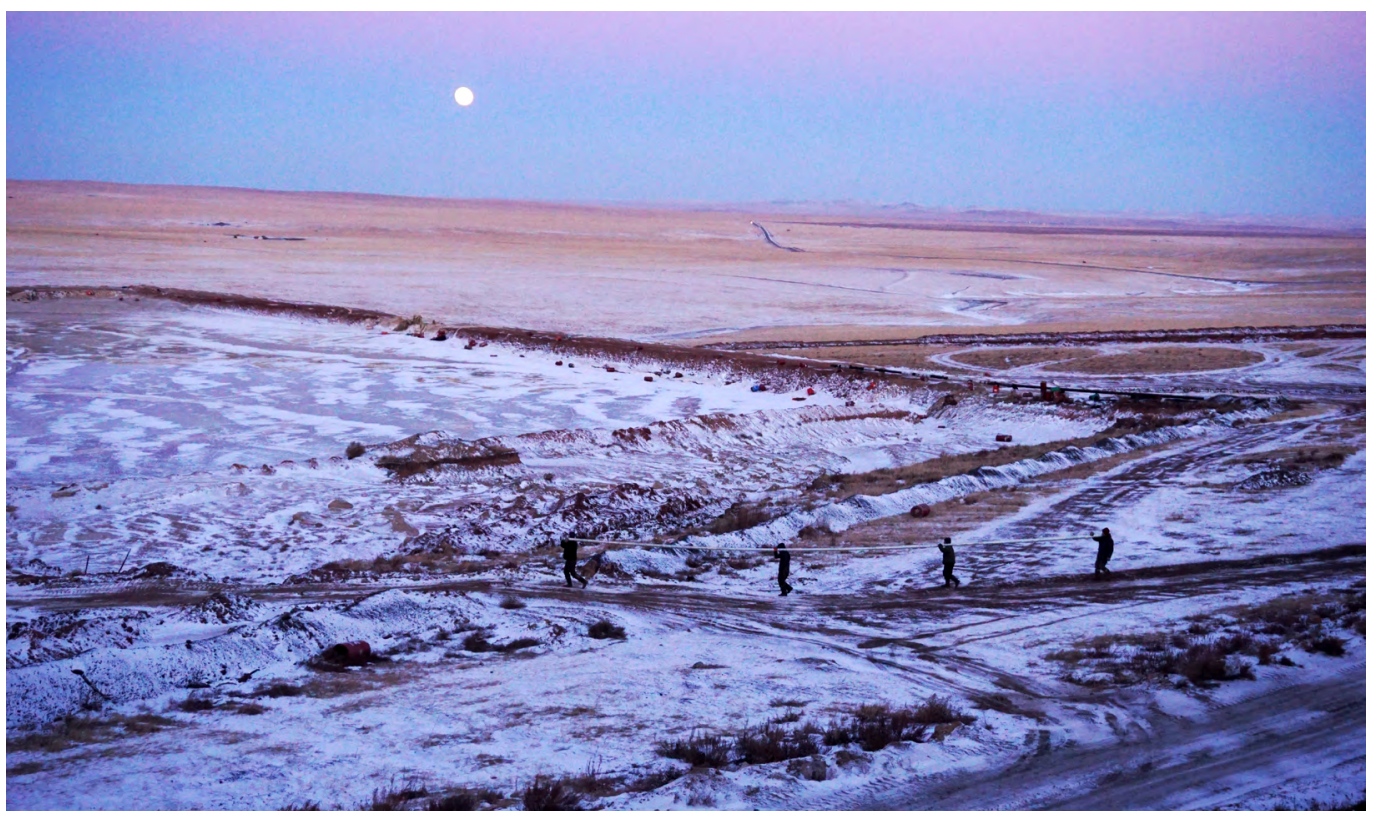

Four workers carry an insulated water pipe across the snow-covered grounds of the mine. PC: Zhu Ruiyi.

early 2000s in China. As mining companies in Mongolia promise higher salaries than equivalent employers in China, middle-aged Chinese workers arrive in Mongolia in search of an economic foothold to support themselves and their families. As a 53-year-old boiler operator at my field site fittingly put it: '[I'm here to] burn my remaining energy [发挥余热].

\section{2}

The field site I describe here is a private fluorspar mine and factory in Mongolia. The mine was explored by Soviet and Mongolian geologists in the late 1980s. After the Soviets' departure, Chinese businessmen bought the mine and transferred it to the current mine boss, who subsequently built a processing plant on site. Since 2013, the mine boss has been recruiting heavily from among his relatives and acquaintances for skilled labour. Of 25 Chinese workers, a majority were middle-aged men hailing from Hunan, Shandong, Jiangxi, and Inner Mongolia. Similar to many smallto-medium-sized enterprises in Mongolia, this factory's hiring process was highly casual. Without effective legal employment protection for foreign labour, Chinese employees relied heavily on their personal rapport with the boss and managers.

Because of Mongolia's legal requirements and prioritisation of employing Mongolian labour, Mongolian workers at my field site outnumbered their Chinese counterparts. Most were also younger, with an averaging 35 years old. Twenty per cent of the Mongolian workers were women. While Chinese workers occupied supervisory positions, Mongolian workers carried out manual labour as assistants. Recruited from the nearby district and industrial towns such as Bor-Öndör and Baga Nuur, most lacked relevant skills. 


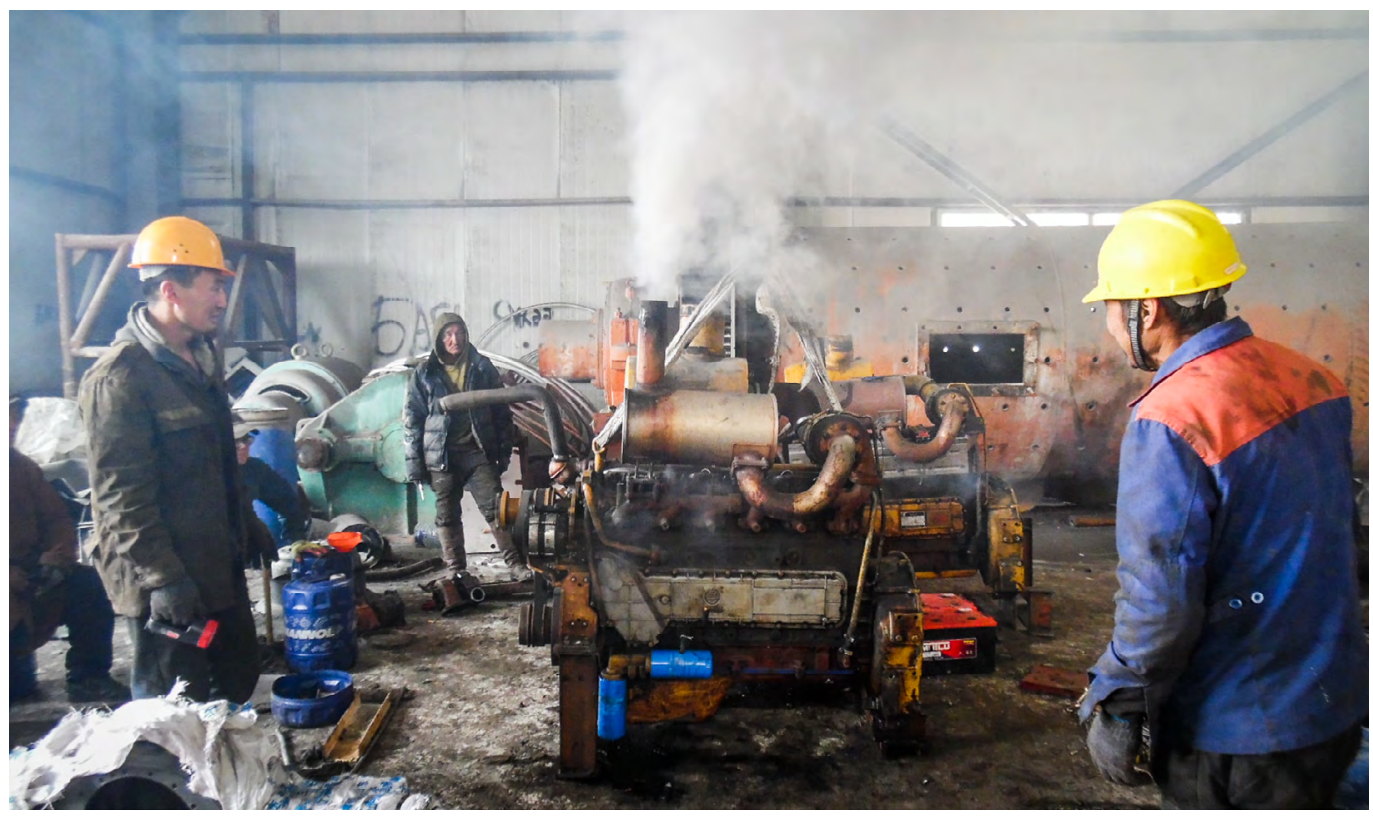

The mechanics feel relieved after spending three days fixing the engine of an extractor. PC: Zhu Ruiyi.

Limited professional training at the factory, compounded by the high turnover rate, reinforced the status quo among unskilled and low-skilled labour.

Being abroad for the first time, Chinese workers initially faced unprecedented challenges. They did not expect to find themselves de facto illiterate on arrival in Mongolia. Without predeparture language training, many complained about their frustration with 'not understanding anything'. Some had hoped to rely on the latest machine translation applications on their smart phones but were soon disappointed to discover that those applications either did not support Mongolian or failed to connect due to poor internet reception in rural areas.

The majority of the Chinese workers spoke only Chinese, with the exception of a few ethnic Mongol and Han workers from Inner Mongolia. An ethnic Mongol worker from Ulaanchab, Inner Mongolia, observed:
90 per cent of the names for industrial tools in the [Halh] Mongolian language spoken here are in fact Russian. If you take a look around the factory, 'crane' [kran], 'excavator' [ekskavator], 'car' [mashin], 'petrol' [bienzin], 'diesel' [dizel'] ... are all Russian words.

This technical vocabulary was mostly new to him, as his own Mongolian language was largely infused with Chinese instead of Russian loanwords. The factory's remote location and poor amenities hardly attracted long-term professional interpreters, who were more inclined towards urban and cosmopolitan settings. Due to the chronic shortage of professional interpreters, bilingual workers from Inner Mongolia, who were not recruited for their linguistic skills, would be asked to undertake an intermediary role and harmonise the inevitable industrial cacophony. 


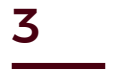

As the Chinese workers held leading positions, they demanded assistance with oral translation more often than their Mongolian counterparts. Without an interpreter, they could spend 10 times more effort to get a message across, with body language carrying high risks of miscommunication. Xu Jun, the crushing section lead, recalled:

Once I asked my Mongolian assistant to make a slanted connector for the ore crusher. I showed him many times the angle of slant with my gestures, but he just did not get it. Do you know what he gave me in return? A straight angle and a blank look. In the end I had to make one myself to show him what I meant. He instantly understood and raised his thumb, saying 'Sain, sain' ['good, good']. I didn't know if I should laugh or cry.

He blamed the incident on the Mongolian worker's 'inflexible brain' rather than acknowledging a communication failure for which both were responsible. Such refusals to share responsibility were not uncommon among monolingual workers. Linguistic miscommunication without timely mediation easily perpetuates essentialist stereotypes. After the incident, Xu Jun would always ask a bilingual person to bridge the linguistic gap. Even though the translation may be imperfect as the intermediary might not know particular technical terms in Mongolian, their colloquial translation of the key actions involved could help the listeners understand.

Liu Xizhou (or Ulzii), the protagonist of the opening vignette, is an example of a bilingual worker and occasional stand-in interpreter. During almost a decade in Mongolia, he built on the smattering of Mongolian he had learned in Inner Mongolia to become fluent in colloquial Mongolian. Unlike his Chinese coworkers, who preferred to live on the Chinese side of the dormitory, Liu, uniquely, chose to live on the
Mongolian side to avoid gossip and retain his 'peace of mind'. As he seldom socialised with the majority of Chinese workers and often took food from the Mongolian dining hall instead of the Chinese one, he was seen as an oddball.

Once, Liu broke his typical silence towards Chinese coworkers following a minor incident. Feng Jinhua, a female laboratory technician, had excitedly broken the news of her discovery of what looked like curative wild herbs on the hills nearby. Not knowing what to do with them and where to find more, she approached Liu for advice. He took a quick look: 'This is wild lily, indeed, used in Chinese medicine to make herbal infusions.' Feng probed further: 'You have been here the longest. You must know where to find more of them.' Liu hesitated before saying:

\section{Of course I do ... But here's a word of advice for you if you want to keep foraging. The Mongolian workers have been talking about the holes you left after uprooting the plants. Uprooting plants and leaving holes on the ground is against Mongolian customs.}

Liu explained: 'Though they don't use lily as we Chinese people do, they care about preserving the environment.' Receptive to Liu's words of caution, Feng promised to fill in the holes the following day. Speaking as a mine veteran and grassroots cultural expert, Liu's words were heeded as consequential in terms of risk management, which effectively protected the reputation of the Chinese workers and the long-term prospects of the mining enterprise in the area.

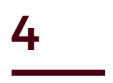

While translation was crucial to facilitating industrial production and mediating interethnic relations, certain words, particularly those with sexual connotations, were carefully kept untranslated. Prior to their 
arrival in Mongolia, most Chinese workers had already heard that sexuality was a sensitive issue in Sino-Mongolian relations. In the postsocialist era, economic structural weakness combined with the rise of nationalism gave rise to anxiety about biological reproduction and racial purity in Mongolia (Bulag 1998). The fear of foreign, particularly Chinese, economic and cultural encroachment manifested in the scramble to control women's bodies and reproduction (Billé 2014). The mining industry, in particular, provokes anxieties about the purity and protection of Mongolian soil. In addition to the fear that mining impoverishes Mongolian land and jeopardises its future, the concentration of Chinese men in industrial zones evokes bitter colonial memories. In the latter half of Qing imperial rule, when Chinese traders were allowed into Outer Mongolia, many lived illicitly with Mongolian women and produced mixed children, while fishing exorbitant interests on long-term debt (Dear 2014; Tsai 2017). Anxieties akin to those of the late imperial era resurface today.

The gender imbalance at the mine constituted fertile ground for such fears to manifest on a local scale. Even though employees did not interact much after work, each retreating to his or her dormitory, the shopfloor was perceived as a site of potential sexual encounters. Rumours about Chinese supervisors accosting Mongolian female workers circulated, which allegedly led to fistfights between angry Mongolian men protecting 'their' women and Chinese men defending their reputation.

Aware of the touchiness of sexuality, Chinese workers established an informal linguistic boundary by speaking only in Chinese when they indulged in sexual banter. To a number of them, talking about sex was a necessary release valve for pent-up frustration and desire exacerbated by their physical isolation from family life. 'We go home only once a year,' old Wang claimed. 'Old men like me may put up with it, but how can you ask a younger man to endure this? It doesn't sit well with human nature.' However, the few 'younger men' blamed the sexual banter on senior Chinese workers, who were, according to them, prone to speech impropriety due to a lack of education, coupled with an old-fashioned culture of abusing supervisorial power.

I was often present when older Chinese men casually exchanged moralistic, if ethnocentric and sexist, remarks on Mongolian gender relations over dinner: 'There are too many single mothers in Mongolia because of alcoholism. Men here are so irresponsible that they abandon the women after impregnating them, without marriage or anything.' In their view, the loose Mongolian attitude to marriage stood in stark contrast to the stability of (idealised) Chinese conjugal relations, according to which the husband's economic provision is met by the wife's labour of care. Although they reunited with their families in China only once a year, they considered themselves responsible husbands on account of their regular provision of remittances. Their choice to contrast their responsibility with the stereotype of irresponsible Mongolian men reinforced their masculinity.

In the past, inexperienced interpreters had committed more than one faux pas by literally translating the content of the sexual banter into Mongolian, thus puncturing the linguistic buffer. When a couple of Mongolian female workers once went to their Chinese supervisor to ask for a pay raise, he jokingly replied: 'If you sleep with me, I will grant your wishes.' The interpreter at the time faithfully delivered the translation, and problems predictably ensued. The supervisor was furious at the interpreter for breaking the implicit consensus about not translating sexual banter, and for stirring interethnic discord by handing Mongolian workers a reason to accuse the Chinese supervisors of impropriety and malpractice. The monolingual Chinese workers expected the interpreter to act as a 'filter' for their foul language by relaying only appropriate information in Mongolian. Of all forms of workplace speech, sexual banter was specifically not intended for translation; it was a form of exclusive sociality among 
Chinese male workers, without intending to create dialogic communication or illocutionary effects on their Mongolian counterparts.

When sexual banter was uttered, it was also used by Chinese monolingual workers to limit their bilingual compatriots' social proximity with Mongolian workers, particularly women. As in the case of Liu Xizhou, his coworker's insinuation of his sexual involvement with the ethnic other brought serious moral disquietude. Liu intimated that he never trusted those Chinese who operated within their own narrow frame of mind: 'They could never imagine genuine friendship between Chinese and Mongols.' The heavy consequence of sexual suspicion was often borne by Mongolian female workers, who could be dismissed for 'causing trouble' after becoming the target of rumours. Compared with the Chinese male workers, who were to varying degrees connected to the mine boss, the position of Mongolian workers' was more precarious. Additionally, coworkers and relatives of Mongolian female workers, particularly protective men, might attempt to control their conduct. A female worker's proximity to her Chinese supervisor could be used to accuse her of behaving inappropriately and betraying Mongolian solidarity. Tsegii, a lab worker in her mid-twenties, confided: 'I can't tell my family about the sexual banter and innuendo Chinese men make in front of me. I know my husband and brothers would beat them up. I don't want to make a mess at my workplace.' Contrary to the Chinese workers' belief that they could successfully contain sexual banter by limiting translation, its injurious effect was felt by their Mongolian counterparts. To save their jobs, Mongolian female workers were complicit in containing the transmission of inflammatory speech.

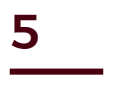

In addition to translation practices that, by restricting and regimenting the interethnic interface, allowed Chinese and Mongolian workers to comfortably remain in their respective linguistic zones (see Pym 2012), the siloed residential arrangements at the factory also contributed to the majority of the workers avoiding learning the other's language. But there were a few individual exceptions. During my stay, I assumed the unofficial role of teaching both Chinese and Mongolian to those workers interested in developing their language skills, and picked up a handful of students. The workers were often interested in practical vocabulary associated with their particular professions. For instance, Dulmaa, a Mongolian kitchen hand, wanted to learn the names of staple foods and ingredients in Chinese so she could bypass the logistics supervisor when borrowing from or lending to the Chinese kitchen. She was surprised to discover that she already knew some Chinese thanks to loanwords in Mongolian. The names of many non-native vegetables-such as cabbage (baitsaa), parsley (yanshui), and leek (juutsai)-trace their etymological roots to Chinese, as do a few staple Mongolian dishes: fried dumplings (huushuur), steamed bun (mantu/buuz), and fried noodles (tsuivan).

In contrast, Chinese workers expressed relatively limited enthusiasm for learning Mongolian. Older workers nearing retirement thought the effort was not worthwhile because they did not wish to stay in Mongolia over the long term. Younger workers thought Mongolian had little use as a transferable skill, unlike English, which they regarded as a true cosmopolitan language. The 31-yearold Tao Xiaochuan was an exception. Despite remaining physically bound to the factory during his three-year stay in Mongolia, he was convinced he had gradually adapted to Mongolian society. Tao first asked to learn the Cyrillic alphabet, and then began to pick up words from work. As a boiler operator, he learned how to say 'turn on', 'turn off', 'start', and 'stop' on his first day. 'I understand so much more about my surroundings with each new word I learn,' he enthused. He initiated a virtual chat group for the Mongolian workers 
in his section to enable instant communication, thus sparing him the need to be near the heater all day.

But in many of his Chinese coworkers' eyes, Tao was simply wasting time 'fooling around' with Mongols. To them, the closer one was to Mongols, the higher were the chances of contracting unwanted social obligations. They preferred sticking to the separate physical and symbolic social spheres as demarcated by the factory management. Laboratory technician Feng Jinhua remarked: 'Mongolian workers always ask you for something: cigarettes, alcohol, or money. They say it's borrowing, but you'll never see the repayment'-a sentiment of unreturned favours that resonated with many Chinese workers. As they felt incapable of holding the Mongolian counterpart accountable with Chinese customs, they chose to keep their distance and avoid social anguish. Liu's judgement seemed judicious: most monolingual Chinese workers were fundamentally dubious about the possibility of forming mutually beneficial friendships with Mongols. Whenever they needed to have contact with Mongols, they relied on the bilinguals to act as risk-free mediators.

6

In conclusion, embedded in the recurring anxieties about power imbalances in SinoMongolian relations, the contemporary Chinese-financed industrial sphere is often perceived in Mongolia as a hot zone for perilous encounters-rife with real or imagined sexual intimacy, linguistic misunderstandings, and cultural conflicts. The contrast between Chinese workers' monolingual and bilingual modes of communication illustrates the limits and possibilities of language when it is differently deployed. Faced with the risks of intercultural communication, maintaining tight linguistic boundaries may guarantee a degree of comfort that most find appealing. The minority of workers who cross the linguistic boundaries, albeit in various capacities, encounter moral dilemmas indicative of the complex power dynamics in which they are embroiled.
[1] All names have been changed to preserve anonymity.

[2] Due to space limitations, this essay focuses only on the bilingual worker-interpreters without discussing the factory's professional interpreters. To illustrate the chronic shortage of onsite professional interpreters during my stay, there were only one or two at best, who were Inner Mongols, huaqiao (diasporic Chinese in Mongolia), or Halh Mongols who learned Chinese language at Mongolian universities or while living in China-the combination changed at different points of my fieldwork. 
This text is taken from Made in China Journal: Volume 5, Issue 3, 2020, edited by Ivan Franceschini and Nicholas Loubere, published 2021 by ANU Press, The Australian National University, Canberra, Australia.

doi.org/10.22459/MIC.05.03.2020.07 